\title{
Association between ambient temperature, particulate air pollution and emergency room visits for conjunctivitis
}

\author{
S. Khalaila ${ }^{1 *}$ (D) T. Coreanu ${ }^{2,3}$, A. Vodonos ${ }^{3}$, I. Kloog $^{4}$, A. Shtein ${ }^{4}$, L. E. Colwell ${ }^{5}$, V. Novack ${ }^{2,3}$ and E. Tsumi ${ }^{1}$
}

\begin{abstract}
Background: Numerous studies have confirmed the association of ambient temperature and air pollution with a higher risk of morbidities, yet few have addressed their effect on the ocular system. The purpose of this study was to assess the association between temperature, air pollution, and emergency room visits for conjunctivitis.

Methods: In this case-crossover study, the records of all emergency room visits to Soroka University Medical Center (SUMC) from 2009 to 2014 were reviewed for patients with conjunctivitis. Daily exposure to fine and coarse particulate matter and temperature were determined by a hybrid model involving satellite sensors. Mean relative humidity was obtained from the Ministry of Environmental Protection meteorological monitoring station located in Beer-Sheva.

Results: Six hundred one patients were diagnosed with conjunctivitis in the SUMC emergency room. We discovered a positive association between temperature increments and incidence of conjunctivitis. The strongest effect was found during summer and autumn, with an immediate (lag0) incidence increase of $8.1 \%$ for each $1{ }^{\circ} \mathrm{C}$ increase in temperature $(\mathrm{OR}=1.088,95 \% \mathrm{Cl}: 1.046-1.132)$ between 24 and $28^{\circ} \mathrm{C}$ in the summer and $7.2 \%$ for each $1{ }^{\circ} \mathrm{C}$ increase in temperature $\left(\mathrm{OR}=1.072,95 \% \mathrm{Cl}\right.$ : 1.036-1.108) between 13 and $23^{\circ} \mathrm{C}$ in the autumn. There was no statistically significant association between fine and coarse particulate matter and conjunctivitis incidence.

Conclusion: Temperature increases during summer and autumn are significantly associated with an increased risk of conjunctivitis. Conjunctivitis is not associated with non-anthropogenic air pollution. These findings may help community clinics and hospital emergency rooms better predict conjunctivitis cases and will hopefully lead to improved prevention efforts that will lower the financial burden on both the individual and the public.
\end{abstract}

Keywords: Conjunctivitis, Temperature, Weather, Air pollution, Ocular disease

\footnotetext{
* Correspondence: kh_soltan@yahoo.com

The authors have no proprietary interest in any of the materials or techniques used in this study.

${ }^{1}$ Department of Ophthalmology, Soroka University Medical Center, P.O. Box

151, 84101 Beer-Sheva, Israel

Full list of author information is available at the end of the article
}

(c) The Author(s). 2021 Open Access This article is licensed under a Creative Commons Attribution 4.0 International License, which permits use, sharing, adaptation, distribution and reproduction in any medium or format, as long as you give appropriate credit to the original author(s) and the source, provide a link to the Creative Commons licence, and indicate if changes were made. The images or other third party material in this article are included in the article's Creative Commons. licence, unless indicated otherwise in a credit line to the material. If material is not included in the article's Creative Commons licence and your intended use is not permitted by statutory regulation or exceeds the permitted use, you will need to obtain permission directly from the copyright holder. To view a copy of this licence, visit http://creativecommons.org/licenses/by/4.0/ The Creative Commons Public Domain Dedication waiver (http://creativecommons.org/publicdomain/zero/1.0/) applies to the data made available in this article, unless otherwise stated in a credit line to the data. 


\section{Background}

Conjunctivitis is an inflammation of the conjunctiva characterized by swelling, redness, discharge, and discomfort. It is a common diagnosis in the general population [7] and the most common ocular condition diagnosed in United States' emergency rooms where it accounts for almost one-third of all eye-related visits [10]. Conjunctivitis scan be infectious (generally caused by adenovirus) or noninfectious (autoimmune, hypersensitivity, etc.).

Conjunctivitis significantly impacts health-care systems; outbreaks can cause significant morbidity, high health-care costs, and loss of workdays, which result in financial burdens on both individuals and the public worldwide $[7,10,36]$. In the United States, 4-6 million conjunctivitis visits annually entail nearly 800 million dollars in treatment costs [36]. The direct effects of the condition on patients' quality of life can vary, ranging from lost school/work to irreversible eye and vision damage. More information about environmental risk factors is crucial to develop measures to reduce the incidence and burden on public health of conjunctivitis [11].

Ambient temperature and air pollution are known to be associated with a variety of health problems and disorders that affect multiple body systems, such as respiratory, cardiovascular, and neurological systems $[1,2,4$, $15,17,28,41-45]$. In severe cases, temperature and air pollution can be fatal to individuals [1, 20, 21, 25]. Several studies have revealed meteorological effects on the ocular system [6, 9, 14, 19, 30, 37, 39], but few agree about the relationship of meteorological changes with conjunctivitis $[5,12,13,18,40]$.

Chia-Jen et al. [12] reported more outpatient visits for conjunctivitis in winter than in summer; however, Chiang et al. [13] reported that average daily visits for acute conjunctivitis peaked in the summer. According to Szyszkowicz et al. [40], the number of visits was higher in the warm season than the cold season. Azari and Barney [7] reported a greater incidence of viral conjunctivitis in summer and bacterial conjunctivitis from December through April. These studies all evaluated the incidence of conjunctivitis by season rather than by temperature.

The present study was undertaken to evaluate the association between air pollution, ambient temperature, and emergency room visits for conjunctivitis in the Negev Desert of southern Israel. This 13, $000 \mathrm{~km}^{2}$ semi-arid region lies between the Saharan and Arabian deserts and the three together constitute the world's largest dust belt. In the light of climate change and desertification, the Negev can be considered a predictor of future climate change in many regions of Europe.

\section{Methods}

\section{Study population}

The study enrolled all patients who arrived at the Soroka University Medical Center (SUMC) Emergency room during the years 2009-2014 and were diagnosed with conjunctivitis. Patients with other eye disorders were used to determine incidence of conjunctivitis compared with other eye complaints. SUMC is a tertiary 1000-bed hospital in the Negev Desert, and the only medical center in the region for a population of 700,000 inhabitants. The Center is owned by the largest health maintenance organization HMO in Israel, Clalit Health Services. Only residents of the southern Negev were enrolled. Demographic and clinical data obtained from the electronic database of Clalit Health Services included date of birth, gender, age, place of residence, eye diseases, and comorbidities.

\section{Air pollution and meteorology data measurement}

Seasons were defined according to Alpert et al. [3]: winter (December 7-March 30), summer (May 31September 22)-each lasts about 4 months-autumn (September 23-December 6), and spring (March 31May 30)-each lasting approximately 2 months.

\section{Air pollution}

There are two main source of air pollution: naturally occurring non-anthropogenic pollutants (such as volcanic eruptions, forest fires, and dust) and anthropogenic air pollutants created by human activity (such as $\mathrm{O}_{3}, \mathrm{NO}_{2}$, $\mathrm{NOX}$, and $\mathrm{SO}_{2}$ ) [34].

We used a hybrid method for assessing spatiotemporal exposure to $\mathrm{PM}_{10}$ (particulate matter $10 \mu \mathrm{m}$ or less in diameter) and $\mathrm{PM}_{2.5}$ (particulate matter $2.5 \mu \mathrm{m}$ or less in diameter) $[22,23,33,38]$. Daily average concentrations were estimated using a hybrid satellite-based model that provides daily satellite remote sensing data at $1 \times 1 \mathrm{~km}$ spatial resolution $[23,38]$ according to the residential address of each patient. Briefly, using the multi-angle implementation to atmospheric correction (MAIAC) algorithm [27], which was developed by NASA and provides aerosol optic depth (AOD) data in high resolution, we applied mixed models to regress daily $\mathrm{PM}_{10}$ and $\mathrm{PM}_{2.5}$ : AOD, traditional land use regression, and temporal and spatial predictors. When AOD was not available, we fitted a generalized additive model with a thin plate spline term of latitude and longitude to interpolate PM estimates. Good model performance was achieved, with out-of-sample cross validation $\mathrm{R}^{2}$ values of 0.92 and 0.87 for $\mathrm{PM}_{10}$ and $\mathrm{PM}_{2.5}$, respectively. Model predictions had little bias, with cross-validated slopes (predicted vs. observed) of close to 1 for both models. Exposure estimates were assigned for each patient based on his/her geocoded home address. The estimates 
provided for PM10 are per $10 \mu \mathrm{g} / \mathrm{m} 3$ changes in air pollution.

\section{Meteorological data}

Daily data on mean air temperature were obtained by a satellite-based model, recently installed by the Israel Meteorological Service for monitoring temperature in the Negev, that provides daily satellite remote sensing data at $1 \times 1 \mathrm{~km}$ spatial resolution for each patient. Mean relative humidity was obtained from the Ministry of Environmental Protection Meteorological monitoring station located in Beer-Sheva, the location of SUMC and the largest city in southern Israel.

\section{Statistical analysis}

The association between air pollution, ambient temperature, and emergency room visits for conjunctivitis was examined using a case-crossover design [29, 31, $32,44,46]$. This design samples only cases and compares each case's exposure to temperature and particulate air pollution during a time period just before the casedefining event (hazard period) with the subject's own exposure in other reference periods (control periods). The hazard period was chosen to be 6 days as this matches the incubation period of conjunctivitis, which in most cases is up to 5-6 days. Because each subject serves as his or her own control, there is perfect matching on all measured or unmeasured subject characteristics that do not vary over time.

We used a symmetric bidirectional case-crossover design. In this design, reference periods are symmetrically spaced in time, both before and after the hazard period, which minimizes potential confounding by season or time trends. In this study, the hazard period was defined as the day of admission; temperature and particulate air pollution exposure was modeled as the exposure on the day of admission and a mean exposure for the 7 days prior to admission. Matched strata were constructed for each subject (that is, admission day) consisting of the event day (day of admission) and six matched control days. These days were chosen to be days $7,14,21$, and 28 before the event and days 7, 14, 21, and 28 after the event.

The statistical analysis included two steps. First, conditional logistic regression [8] models were used to test a possible non-linear association of daily mean temperature with incidence of conjunctivitis for lag 0 to lag 6 and the cumulative effect of 7 days. To allow a non-linear effect of temperature we used penalized splines with five degrees of freedom for temperature and $\mathrm{PM}_{10}$. Models were adjusted for relative humidity as a linear term.

Next we performed a conditional logistic regression to calculate odds ratios (OR) and 95\% confidence intervals
(CI) for lag 0 to lag 6 on risk of conjunctivitis with the main exposure daily mean temperature controlled for $\mathrm{PM}_{10}$ and humidity. Stratified analysis by season (fall, winter, spring, summer), gender (female, male), and age (0-18 years old, $18-65$ years old, and over 65 years old) was performed.

Statistical analysis was performed with the IBM SPSS Statistics software package (version 23.0, IBM, Armonk, $\mathrm{NY}$ ) and R statistical software (version 3.5.1).

The study was conducted according to the Declaration of Helsinki and approved by the Medical Helsinki Committee of the Soroka University Medical Center, Ben-Gurion University of the Negev.

\section{Results}

\section{Population}

Of 19,264 visits to the ophthalmology SUMC emergency room between 2009 and 2014, 6001 (31.1\%) were diagnosed with conjunctivitis (Table 1 in the appendix). The mean age of the patients was 34.6 years (range 0.5-96 years) and $54.4 \%$ were male (Table 2 in the appendix). The majority of patients, $4063(67.7 \%)$, were between 16 and 65 years of age.

\section{Pollution and meteorology}

The average daily levels of meteorological and air pollution variables by seasons are presented in Table 1 . The interquartile range (IQR) of $\mathrm{PM}_{2.5}$ was $17.21-24.82 \mu \mathrm{g} /$ $\mathrm{m}^{3}$ and the maximum value reached was $53 \mu \mathrm{g} / \mathrm{m}^{3}$, with no significant differences between seasons. The IQR of $\mathrm{PM}_{10}$ was $38.44-56.66 \mu \mathrm{g} / \mathrm{m}^{3}$ and the maximum value reached was $193 \mu \mathrm{g} / \mathrm{m}^{3}$; it tended to be slightly higher during the winter. The climate in the study region is relatively hot and dry, with Köppen climate classification type Csa [35]. Average daily IQR temperatures are $11.86-15.65^{\circ} \mathrm{C}$ in winter, $18.64-20.95^{\circ} \mathrm{C}$ in spring, $25.06-27.32{ }^{\circ} \mathrm{C}$ in summer, and $17.02-23.39^{\circ} \mathrm{C}$ in autumn. The IQR relative humidity range was 57.00 $75.00 \%$, with no difference between seasons.

\section{Effect of air pollution on the incidence of conjunctivitis}

ORs and 95\% CIs were estimated from conditional logistic regression analysis of association between $\mathrm{PM}_{2.5}$, $\mathrm{PM}_{10}$ (separately), temperature, and emergency room visits due to conjunctivitis: models were adjusted for humidity. There was no statistically significant correlation between levels of $\mathrm{PM}_{2.5}$ or $\mathrm{PM}_{10}$ and the incidence of conjunctivitis (Table 3 in the appendix).

\section{Effect of temperature on the incidence of conjunctivitis}

A subgroup analysis was conducted to assess the seasonal relationship between temperature and conjunctivitis. The number of emergency room visits for conjunctivitis was higher in summer $(36.4 \%, p<0.001)$ 
Table 1 Air pollution and meteorology values between the years 2009 and 2014

\begin{tabular}{|c|c|c|c|c|c|}
\hline & & Winter $^{\mathrm{a}}$ Dec 7-Mar 30 & Spring ${ }^{\mathrm{a}}$ Mar 31-May 30 & Summera May 31-Sep 22 & Autumn ${ }^{\text {SSep 23-Dec } 6}$ \\
\hline \multirow[t]{4}{*}{$\mathrm{PM}_{2.5} \mu \mathrm{gg} / \mathrm{m}^{3}$} & IQR & $17.52-24.82$ & $17.38-23.14$ & $18.11-22.05$ & $17.21-22.91$ \\
\hline & Mean \pm SD & $22.62 \pm 8.30$ & $21.34 \pm 6.42$ & $20.46 \pm 3.74$ & $20.60 \pm 5.21$ \\
\hline & Minimum & 5.28 & 8.33 & 9.69 & 5.28 \\
\hline & Maximum & 53 & 53 & 53 & 53 \\
\hline \multirow[t]{4}{*}{$\mathbf{P M}_{10} \mathrm{\mu g} / \mathrm{m}^{3}$} & IQR & $39.10-56.66$ & $40.13-51.62$ & $40.39-47.04$ & $38.44-52.68$ \\
\hline & Mean \pm SD & $56.18 \pm 34.35$ & $49.51 \pm 20.94$ & $44.40 \pm 8.92$ & $47.96 \pm 17.95$ \\
\hline & Minimum & 11.53 & 21.08 & 40.39 & 11.53 \\
\hline & Maximum & 193 & 193 & 193 & 193 \\
\hline \multirow[t]{4}{*}{ Temperature ${ }^{\circ} \mathrm{C}$} & IQR & $11.86-15.65$ & 18.64-20.95 & $25.06-27.32$ & $17.02-23.39$ \\
\hline & Mean \pm SD & $13.94 \pm 3.42$ & $20.90 \pm 3.33$ & $26.14 \pm 1.81$ & $20.16 \pm 4.40$ \\
\hline & Minimum & 3.55 & 7.34 & 16.55 & 4.15 \\
\hline & Maximum & 28.11 & 30.87 & 33.62 & 29.80 \\
\hline \multirow[t]{4}{*}{ Relative humidity (\%) } & IQR & $57.00-75.00$ & $52.00-71.50$ & $63.00-71.54$ & $57.00-71.40$ \\
\hline & Mean \pm SD & $65.43 \pm 13.83$ & $59.66 \pm 13.68$ & $66.46 \pm 8.20$ & $62.70 \pm 13.40$ \\
\hline & Minimum & 15.53 & 13.00 & 17.00 & 13.00 \\
\hline & Maximum & 92.45 & 81.77 & 81.77 & 93.14 \\
\hline
\end{tabular}

${ }^{\text {a }}$ Seasons defined according to Alpert et al. [3]

than in winter $(26.0 \%, \mathrm{p}<0.001)$, autumn $(22.1 \%, p=$ $0.773)$, and spring $(15.4 \%, p=0.135)$, with the highest rates recorded in July and August (Fig. 1) (Table 1 in the appendix). When the incidence of conjunctivitis was compared with other ophthalmological disorders by season (Table 1 in the appendix), it was found to be significantly higher in summer (36.4 and $32.8 \%$, respectively, $p<0.001)$ and significantly lower in winter (26.0 and $28.6 \%$, respectively, $\mathrm{p}<0.001)$.

The same results were obtained when the data were stratified by age, with summer leading in each age group $(\mathrm{p}<0.001)$. When analyzed by month, July and August had the highest incidence for each age group (Fig. 1 and Table 4 in the appendix). Multivariate analysis showed no association between the incidence of conjunctivitis and age.

Women were found to have a significant association between temperature and conjunctivitis on all seven day lags and men were found to have a significant association on lags 0 and 6 (Table 5 in the appendix).

There is an overall non-linear association between temperature and conjunctivitis. However, for certain temperature ranges in summer and autumn, we noticed a form of linear positive association between temperature increment and incidence of conjunctivitis (Fig. 2). In summer, the incidence of conjunctivitis increased by $8.1 \%$ (95\%CI: $1.046-1.132)$ with each $1{ }^{\circ} \mathrm{C}$ rise in temperatures between 24 and $28^{\circ} \mathrm{C}$, and for autumn the incidence increased by $7.2 \%$ (95\%CI: $1.036-1.108$ ) with each $1{ }^{\circ} \mathrm{C}$ rise in temperatures between 13 and $23^{\circ} \mathrm{C}$. This association remained after taking into account a 6-day lag between exposure and developing conjunctivitis for both autumn and summer. There was no association between temperature and conjunctivitis during spring and winter (Fig. 2).

\section{Discussion}

The main result of our study is the significant association between temperature and the incidence of conjunctivitis during a range of temperatures in summer and autumn. These temperature ranges $\left(13-23^{\circ} \mathrm{C}\right.$ in autumn and $24-28^{\circ} \mathrm{C}$ in summer) are considered the normal temperatures for most days in these specific seasons, with very few days having temperatures outside of these ranges. Thus, there were no reliable statistical conclusions outside these ranges. No association was found between air pollution $\left(\mathrm{PM}_{2.5}, \mathrm{PM}_{10}\right)$ and the incidence of conjunctivitis.

Meteorological changes and air pollution have been a public health concern for several decades due to accelerated global warming and desertification. Contemporary studies document the effect of temperature and air pollution on human morbidities, especially cardiovascular, respiratory, and neurological systems, as well as on human mortality, even within the normal range of temperatures [1].

Several studies have investigated the association between meteorological changes and ocular diseases. $\mathrm{Hu}$ et al. [19] found that primary angle closure glaucoma admission rates became significantly higher with 

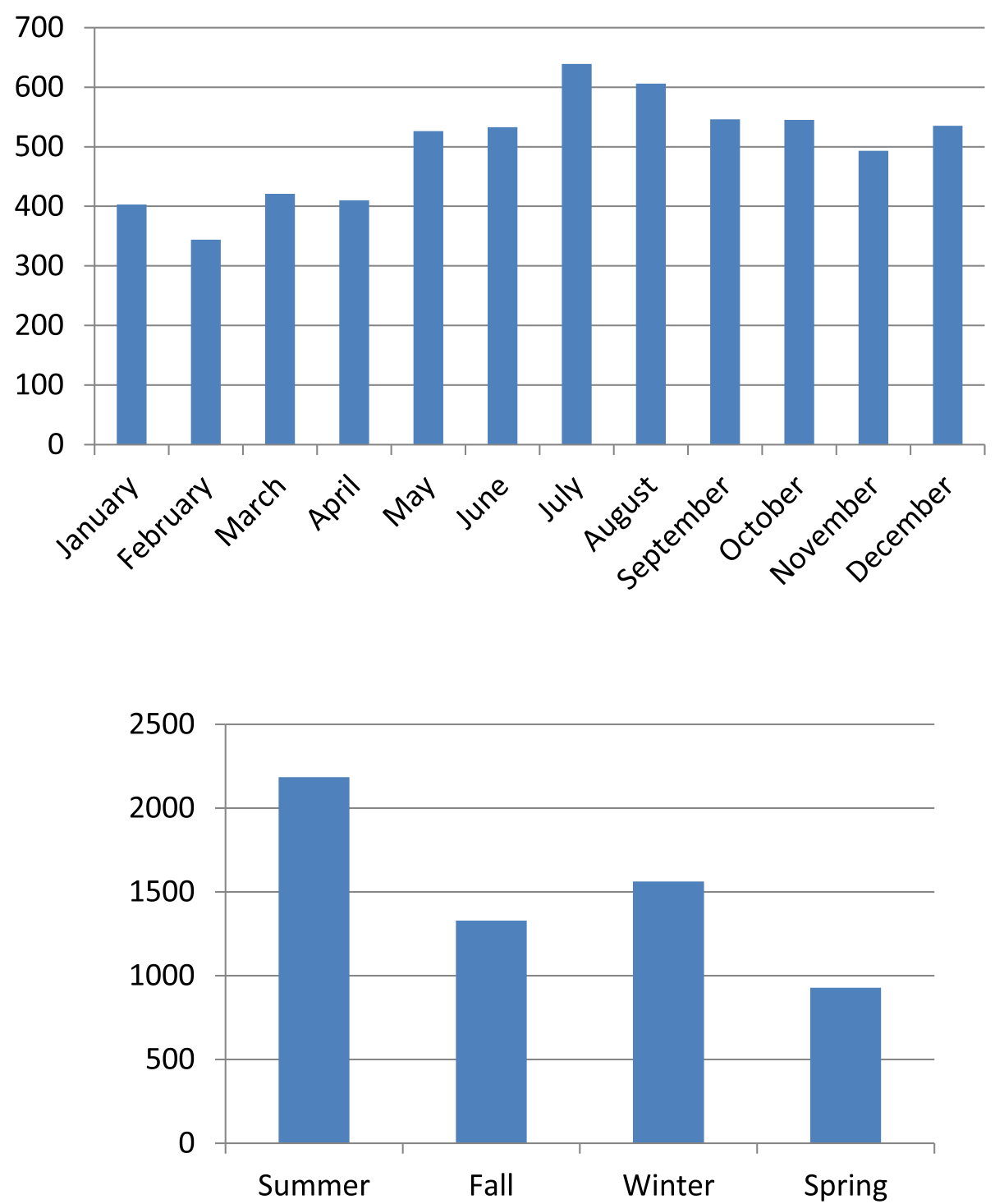

Fig. 1 Rate of conjunctivitis by $\mathbf{a}$. season and $\mathbf{b}$. month

increased relative humidity but showed no correlation to temperature. Matthew et al. [30] reported a higher frequency of infectious keratitis during the higher temperatures and humidity levels of summer. Even an increased risk of tractional retinal detachment was linked to elevated outdoor temperatures by Augera et al. [6]. Furthermore Christoph et al. [14] supported a correlation between higher weekly average temperature and increased ophthalmology emergency room visits.

Few studies have investigated the effect of temperature on conjunctivitis: even those studies examining seasonal conjunctivitis incidence have not accounted for temperature directly $[13,18,40]$.

The pathophysiological mechanisms of air pollution and meteorological changes on conjunctiva remain to be characterized. Some studies [16, 26] have speculated that $\mathrm{PM}_{2.5}$ and $\mathrm{PM}_{10}$ particles cause intraocular epidermal cells to lose their ability to adapt, leading to cell death and inflammation. Krishna et al. [24] pointed to the strong oxidative stress effect of $\mathrm{NO}_{2}$ and $\mathrm{O}_{3}$ that may stimulate conjunctival cell inflammation. Although various authors have related subtypes of conjunctivitis to specific seasons-viral conjunctivitis is common in summer, bacterial in winter, allergic in spring-there is no consensus among them on the exact mechanisms in play $[7,13,18,40]$.

In the Negev Desert, there is little anthropogenic (chemical) pollution, supporting our finding that nonanthropogenic air pollution is not related to conjunctivitis without the confounding effect of anthropogenic pollution. However, other studies in other locations may 

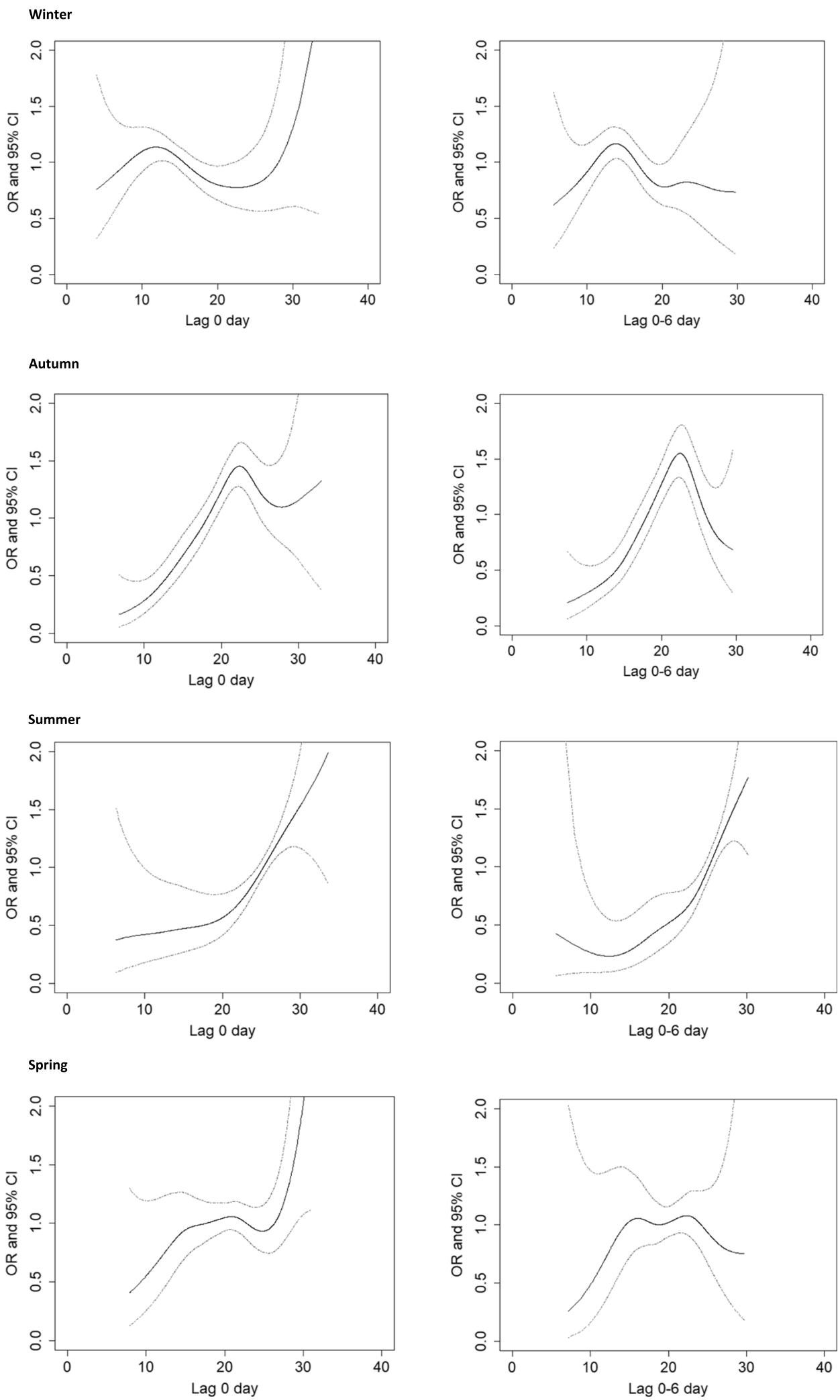

Fig. 2 Association between increase in temperature and visits to the emergency room for conjunctivitis, by season. The solid lines are the odds ratios (ORs) and the dotted lines are $95 \%$ confidence intervals. Models were adjusted for humidity and PM $_{10}$ 
have had chemical pollution confound the effect of PM on the incidence of conjunctivitis.

Our findings of seasonal differences in the incidence of conjunctivitis agree with those of Hong and coworkers [18]: higher levels of temperature and lower humidity lead to increased outpatient visits for allergic conjunctivitis, which is potentially due to pollen production in warmer temperatures. In our study, we investigated the meteorological effect on non-specific conjunctivitis whereas the Hong et al. study targeted allergic conjunctivitis. Furthermore, our study measured exact temperatures in relation to each patient's condition whereas Hong et al. grouped patients by season. Chiang et al. [13] found the incidence of chronic conjunctivitis to peak in summer, more so in rural than urban areas, a difference they attributed to factors such as socioeconomic status, income, and occupation. Szyszkowicz et al. [40] found that the number of visits to the emergency room due to conjunctivitis was higher in warm seasons (58\%) than cold seasons (42\%), which was also seen in our study. However, these authors studied the effect by season and not, as we did, by temperature.

The statistically significantly higher incidence of conjunctivitis in summer compared with winter suggests that higher temperatures are a risk for conjunctivitis and lower temperatures are protective against conjunctivitis. We determined that certain temperature ranges are associated with the incidence of conjunctivitis in summer and autumn. However, the lack of association between temperature and conjunctivitis in spring (moderate climate), and winter (cold climate) indicates that there is a multifactorial relationship and other factors involved. Further research is needed to understand more of these factors.

\section{Limitations}

Although our study focuses on a specific climatic region with dry, hot, semi-desert conditions and involves a limited population, ours is a tertiary hospital and the only one in the region. We did not select the sample for the study but included the entire population.

\section{Conclusions}

Temperature is significantly associated with conjunctivitis in southern Israel during summer and autumn. The incidence of conjunctivitis is significantly higher than other eye disorders in summer and lower in winter. There is no association between non-anthropogenic air pollution and conjunctivitis.

These findings can help community clinics and hospital emergency rooms prepare for the upticks in conjunctivitis following acute rises in temperature during certain seasons.

\section{Supplementary Information}

The online version contains supplementary material available at https://doi. org/10.1186/s12886-021-01854-1.

\section{Additional file 1.}

\section{Abbreviations}

AOD: Aerosol optic depth; PM: Particulate matter; IQR: Interquartile range; $\mathrm{O}_{3}$ : Trioxygen; $\mathrm{NO}_{2}$ : Nitrogen dioxide; $\mathrm{NOX}$ : Nitric oxide; $\mathrm{SO}_{2}$ : Sulfur-dioxide

\section{Authors' contributions}

All authors have read and approved the manuscript. SK: Conception or design of the work; data collection; data analysis and interpretation; drafting the article. TC: Data collection and data analysis and interpretation. AV: Critical revision of the article. IK: Data analysis and interpretation. AS: Data analysis and interpretation. LC: Revision of the article. VN: Critical revision of the article. ET: Conception or design of the work; Critical revision of the article.

\section{Funding}

The authors received no financial support for the research, authorship, and/ or publication of this article.

\section{Availability of data and materials}

The raw data that support the findings of this study are available from Soroka Medical Database Center but restrictions apply to the availability of these data, which were used under license for the current study, and so are not publicly available. Data are however available from the authors upon reasonable request and with permission of Soroka Medical Database Center. All other data generated or analyzed during this study are included in this article and its supplementary information files.

\section{Ethics approval and consent to participate}

The study was conducted according to the Declaration of Helsinki and approved by the Medical Helsinki Committee of the Soroka University Medical Center, Ben-Gurion University of the Negev.

Permission to access data was obtained by the Medical Helsinki Committee of the Soroka University Medical Center, Ben-Gurion University of the Negev. No personal data was obtained in the study and consent to participate was not required by the Medical Helsinki Committee of the Soroka University Medical Center, Ben-Gurion University of the Negev (approval \#: 0407-16SOR).

\section{Consent for publication}

not required.

The manuscript does not include details, images, or videos relating to a person.

\section{Competing interests}

The authors declare that they have no competing interests.

\section{Author details}

${ }^{1}$ Department of Ophthalmology, Soroka University Medical Center, P.O. Box 151, 84101 Beer-Sheva, Israel. ${ }^{2}$ Faculty of Health Sciences, Ben-Gurion University of the Negev, Beer-Sheva, Israel. ${ }^{3}$ Negev Environmental Health Research Institute, Soroka University Medical Center, P.O. Box 151, 84101 Beer-Sheva, Israel. ${ }^{4}$ Department of Geography and Environmental Development, Ben-Gurion University of the Negev, Beer-Sheva, Israel. ${ }^{5}$ University of Massachusetts Medical School, Worcester, MA, USA.

Received: 17 June 2019 Accepted: 9 February 2021

Published online: 24 February 2021

\section{References}

1. Aditi B, Jan W, Alina V, Nicholas H, Joacim R, Shakoor H, Rainer S. Effects of air temperature on climate-sensitive mortality and morbidity outcomes in 
the elderly; a systematic review and meta-analysis of epidemiological evidence. EBioMedicine. 2016;6:258-68.

2. Alina V, Victor N, Yair Z, Gal I. Ambient air pollution, weather and daily emergency department visits for headache. Cephalalgia. 2015;35:1085-91.

3. Alpert P, Osetinsky I, Ziv B, Shafir H. A new seasons definition based on classified daily synoptic systems: An example for the eastern Mediterranean. Int J Climatol. 2004;24:1013-21.

4. Anderson GB, Dominici F, Wang Y, McCormack MC, Bell ML, Peng RD. Heat related emergency hospitalizations for respiratory diseases in the Medicare population. Am J Respir Crit Care Med. 2013;187:1098-103.

5. Andre A, Miranda T, Priscila N, Monique M, Milton RA, Mario LR. Ocular surface adverse effects of ambient levels of air pollution. Arq Bras Oftalmol. 2011;74:377-82

6. Augera N, Rhéaumea M, Bilodeau MB, Tangd T, Kosatskye T. Climate and the eye: case-crossover analysis of retinal detachment after exposure to ambient heat. Environ Res. 2017;157:103-9.

7. Azari A, Barney N. Conjunctivitis: a systematic review of diagnosis and treatment. JAMA. 2013;310:1721-30.

8. Bateson TF, Schwartz J. Control for seasonal variation and time trend in case-crossover studies of acute effects of environmental exposures. Epidemiology. 1999;10:539-44.

9. Bourcier T, Viboud C, Cohen JC, Thomas F, Bury T, Cadiot L, Mestre O, Flahault A, Borderie V, Laroche L. Effects of air pollution and climatic conditions on the frequency of ophthalmological emergency examinations. Br J Ophthalmol. 2003;87:809-11.

10. Channa R, Zafar N, Canner J. Epidemiology of eye-related emergency department visits. JAMA Ophthalmol. 2016;134:312-9.

11. Chen R, Yang J, Zhang C, Li B, Bergmann S, Zeng F, Wang H, Wang B. Global associations of air pollution and conjunctivitis diseases: a systematic review and meta-analysis. J Environ Res Public Health. 2019;16:3652.

12. Chia-Jen C, Hsi-Hsien Y, Chin-An C, Hsien-Yang T. Relationship between air pollution and outpatient visits for nonspecific conjunctivitis. IOVS. 2012:53:429-33.

13. Chiang C, Liao C, Chen P, Tsai Y, Wang Y. Population study on chronic and acute conjunctivitis associated with ambient environment in urban and rural areas. J Expo Sci Environ Epidemiol. 2012;22:533-8

14. Christoph K, Karsten K, Michael M, Florian R, Wolfgang M, Siegfried P, Thomas K. Correlation between weather and incidence of selected ophthalmological diagnoses: a database analysis. Clin Ophthalmol. 2016;10:1587-92.

15. Eccles R. An explanation for the seasonality of acute upper respiratory tract viral infections. Acta Otolaryngol. 2002;122:183-91.

16. Gao ZX, Song XL, Li SS, Lai XR, Yang YL, Yang G, Li ZJ, Cui YH, Pan HW. Assessment of DNA damage and cell senescence in corneal epithelial cells exposed to airborne particulate matter (PM2.5) collected in Guangzhou, China. Investig Ophthalmol Vis Sci. 2016;57:3093-102.

17. Gerber Y, Jacobsen SJ, Killian JM, Weston SA, Roger VL. Seasonality and daily weather conditions in relation to myocardial infarction and sudden cardiac death in Olmsted County, Minnesota, 1979 to 2002. J Am Coll Cardiol. 2006; 48:287-92

18. Hong J, Zhong T, Li H, Xu J, Ye X, Mu Z, Lu Y, Mashaghi A, Zhou Y, Tan M, Li Q, Sun X, Liu Z, Xu J. Ambient air pollution, weather changes, and outpatient visits for allergic conjunctivitis: a retrospective registry study. Sci Rep. 2016;6:23858.

19. Hu C, Lin H, Chen C. A 7-year population study of primary angle closure glaucoma admissions and climate in Taiwan. Ophthalmic Epidemiol. 2007; 15:66-72.

20. Jhun I, Mata D, Nordio F, Lee M, Schwartz J, Zanobetti A. Ambient temperature and sudden infant death syndrome in the United States. Epidemiology. 2017;28:728-34.

21. Jun $Y$, Maigeng Z, Peng $Y$, Mengmeng L, Xiaobo L, Haixia W, Qiyong L. National and regional death burden attributable to ambient temperatures: epidemiological evidence from 89 Chinese communities. Lancet. 2016:388:24

22. Kloog I, Chudnovsky AA, Just AC, Nordio F, Koutrakis P, Coull BA, Lyapustin A, Wang Y, Schwartz J. A new hybrid spatio-temporal model for estimating daily multi-year pm2.5 concentrations across northeastern USA using high resolution aerosol optical depth data. Atmos Environ. 2014;95:581-90.

23. Kloog I, Sorek-Hamer M, Lyapustin A, Coull B, Wang Y, Just AC, Schwartz J, Broday DM. Estimating daily PM 2.5 and PM 10 across the complex geoclimate region of Israel using MAIAC satellite-based AOD data. Atmos Environ. 2015;122:409-16.
24. Krishna M, Springall D, Frew A, Polak J, Holgate S. Mediators of inflammation in response to air pollution: a focus on ozone and nitrogen dioxide. J R Coll Physicians Lond. 1996;30:61-6.

25. Lelieveld J, Evans J, Fnais M, Giannadaki D, Pozzer A. The contribution of outdoor air pollution sources to premature mortality on a global scale. Nature. 2015;525:367-71.

26. Li J, Tan G, Ding X, Wang Y, Wu A, Yang Q, Ye L, Shao Y. A mouse dry eye model induced by topical administration of the air pollutant particulate matter 10. Biomed Pharmacother. 2017:96:524-34

27. Lyapustin A, Martonchik J, Wang Y, Laszlo I, Korkin S. Multiangle implementation of atmospheric correction (MAIAC): 1 Radiative transfer basis and look-up. tables J Geophys Res. 2011;116(D3).

28. Maayan Y, Victor N, Gal I, Anat H, Itai K. Air pollution and ischemic stroke among young adults. Stroke. 2015;46:3348-53.

29. Maclure M. The case-crossover design: a method for studying transient effects on the risk of acute events. Am J Epidemiol. 1991;133:144-53.

30. Matthew G, Alina G, Sharon Y, Ahmed A, Douglas L. Seasonal variation in the presentation of infectious keratitis. Eye Contact Lens. 2016;42:295-7.

31. Mieczysław S, Termeh K, Jessica C. Air pollution and emergency department visits for conjunctivitis: a case-crossover study. Int J Occup Med Environ Health. 2016;29:381-93.

32. Navidi W. Bidirectional case-crossover designs for exposures with time trends. Biometrics. 1998:54:596-605

33. Nordio F, Kloog I, Coull B, Chudnovsky A, Grillo P, Bertazzi P, Baccarelli A, Schwartz J. Estimating spatio-temporal resolved PM10 aerosol mass concentrations using MODIS satellite data and land use regression over Lombardy. Italy Atmos Environ. 2013;74:227-36.

34. Popescu F, lonell I. (2010) Anthropogenic air pollution sources, air quality, Ashok Kumar (Ed.), ISBN: 978-953-307-131-2, InTech, p. 14 Available from: http://www. intechopen.com/books/airquality/anthropogenic-air-pollution-sources.

35. Rubel F, Kottek M. Comments on: "the thermal zones of the earth" by Wladimir Köppen (1884). Meteorol Z. 2011;20:361-5.

36. Schneider J, Scheibling C, Segall D, Sambursky R, Ohsfeldt R, Lovejoy L. Epidemiology and economic burden of conjunctivitis: a managed care perspective. J Manag Care Med. 2014;17:78-83.

37. Setten G, Labetoulle M, Baudouin C, Rolando M. Evidence of seasonality and effects of psychrometry in dry eye disease. Acta Ophthalmol. 2016;94:499-506.

38. Shtein A, Karnieli A, Katra I, Raz R, Levy I, Lyapustin A, Dorman M, Broday DM, Kloog I. Estimating daily and intra-daily PM10 and PM2.5 in Israel using a spatio-temporal hybrid modeling approach. Atmos Environ. 2018;191:142-52.

39. Stein J, Pasquale L, Talwar N, Kim D, Reed D, Nan B, Kang J, Wiggs J, Richards J. Geographic and climatic factors associated with exfoliation syndrome. Arch Ophthalmol. 2011;129:1053-60.

40. Szyszkowicz M, Kousha T, Castner J. Air pollution and emergency department visits for conjunctivitis: a case-crossover study. Int J Occup Med Environ Health. 2016;29:381-93.

41. Vencloviene J, Babarskiene RM, Dobozinskas P, Sakalyte G, Lopatiene K, Mikelionis N. Effects of weather and heliophysical conditions on emergency ambulance calls for elevated arterial blood pressure. Int J Environ Res Public Health. 2015a;12:2622-38.

42. Vencloviene J, Babarskiene R, Dobozinskas P, Siurkaite V. Effects of weather conditions on emergency ambulance calls for acute coronary syndromes. Int J Biometeorol. 2015b;59:1083-93.

43. Vodonos A, Friger M, Katra I, Avnon L, Krasnov H, Koutrakis P, Schwartz J, Lior O, Novack V. The impact of desert dust exposures on hospitalizations due to exacerbation of chronic obstructive pulmonary disease. Air Qual Atmos Health. 2014;7:433-9.

44. Vodonos A, Friger M, Katra I, Krasnov H, Zahger D, Schwartz J, Novack V. Individual effect modifiers of dust exposure effect on cardiovascular morbidity. PLoS One. 2015;10:e0137714.

45. Yang AC, Fuh JL, Huang NE, Shia BC, Peng CK, Wang SJ. Temporal associations between weather and headache: analysis by empirical mode decomposition. PLoS One. 2011;6:e14612.

46. Yitshak-Sade M, Novack V, Katra I, Gorodischer R, Tal A, Novack L. Nonanthropogenic dust exposure and asthma medication purchase in children. Eur Respir J. 2015;45:652-60.

\section{Publisher's Note}

Springer Nature remains neutral with regard to jurisdictional claims in published maps and institutional affiliations. 